\title{
Rational synthesis of $\mathrm{SnS}_{2} @ \mathrm{C}$ hollow microspheres with superior stability for lithium-ion batteries
}

\author{
Hulin Yang ${ }^{1 \dagger}$, Yanhui Su${ }^{1 \dagger}$, Lin Ding ${ }^{1}$, Jiande $\operatorname{Lin}^{1}$, Ting $\mathrm{Zhu}^{{ }^{*}}$, Shuquan Liang ${ }^{1}$, Anqiang Pan ${ }^{1^{*}}$ and \\ Guozhong $\mathrm{CaO}^{2}$
}

\begin{abstract}
Tin-based nanomaterials have been extensively explored as high-capacity anode materials for lithium ion batteries (LIBs). However, the large volume changes upon repeated cycling always cause the pulverization of the electrode materials. Herein, we report the fabrication of uniform $\mathrm{SnS}_{2} @ \mathrm{C}$ hollow microspheres from hydrothermally prepared $\mathrm{SnO}_{2} @ \mathrm{C}$ hollow microspheres by a solid-state sulfurization process. The as-prepared hollow SnS $\mathrm{S}_{2} \mathrm{C}$ microspheres with unique carbon shell, as electrodes in LIBs, exhibit high reversible capacity of $814 \mathrm{~mA} \mathrm{~h} \mathrm{~g}^{-1}$ at a current density of $100 \mathrm{~mA} \mathrm{~g}^{-1}$, good cycling performance $\left(783 \mathrm{~mA} \mathrm{~h} \mathrm{~g}^{-1}\right.$ for 200 cycles maintained with an average degradation rate of $0.02 \%$ per cycle) and remarkable rate capability (reversible capabilities of $433 \mathrm{~mA} \mathrm{~h} \mathrm{~g}^{-1}$ at $2 \mathrm{C}$ ). The hollow space could serve as extra space for volume expansion during the charge-discharge cycling, while the carbon shell can ensure the structural integrity of the microspheres. The preeminent electrochemical performances of the $\mathrm{SnS}_{2} @ \mathrm{C}$ electrodes demonstrate their promising application as anode materials in the next-generation LIBs.
\end{abstract}

Keywords: tin disulfide, hollow microspheres, lithium-ion battery, anode material, carbon coating

\section{INTRODUCTION}

As one of the most successful power sources, lithium ion batteries (LIBs) have dominated the power market of high-tech electronic devices and electrical vehicles due to their high energy density [1-3]. However, the ever-increasing requirements from the customers stimulate the continuous efforts to develop advanced electrode materials with high energy density, good stability, low-cost and good safety [4]. The relatively low storage capacity of commercial graphite anode $\left(372 \mathrm{~mA} \mathrm{~h} \mathrm{~g}^{-1}\right)$ cannot meet the high energy density requirement for the next-generation LIBs [5]. To address this issue, tin and tin-based materials (such as $\mathrm{SnO}, \mathrm{SnO}_{2}$, and $\mathrm{SnS}_{2}$ ) have been extensively studied as the alternative anodes owing to their low operating voltage, high theoretical capacities and low cost [6-9]. Among them, $\mathrm{SnS}_{2}$ has been suggested as a promising candidate for LIBs anodes because of its $\mathrm{CdI}_{2}$ type layered structure, in which the tin atoms are sandwiched between two layers of hexagonally close-packed sulfur atoms. The neighboring sulfur layers bonded by the weak Van der Waals interactions facilitate kinetically for $\mathrm{Li}^{+}$insertion and extraction $[10,11]$. This space among the layers, as a host for insertion and extraction of $\mathrm{Li}^{+}[12,13]$, contributes to a high theoretical capacity. Compared with the tetragonal rutile $\mathrm{SnO}_{2}$, the $\mathrm{CdI}_{2}$-type layered structure of $\mathrm{SnS}_{2}$ is more favorable for the cycle performance of electrode, because the layers with weak interaction are more flexible for repeated insertion and extraction of ions. Moreover, the $\mathrm{Li}_{2} \mathrm{~S}$, produced by the irreversible reaction of $\mathrm{SnS}_{2}$ and $\mathrm{Li}^{+}$, can serve as a buffer in $\mathrm{Li}-\mathrm{Sn}$ alloying-dealloying process. Unfortunately, the intrinsically low electrical conductivity and extremely large volume change (approximate 300\% during lithiation and delithiation) lead to capacity decay, commonly reported for tin-based anode materials [14], and poison the electrochemical performance of $\mathrm{SnS}_{2}$ electrode materials [15].

Many efforts have been endeavored to make nanostructured $\mathrm{SnS}_{2}$ or their composites. Because rational morphological design of active materials can relieve internal stress caused by volumetric expansion and thus protect the microstructure from collapse during the diffusion of ions. Moreover, minimizing particle sizes can shorten the diffusion distance of lithium ions and the electronic transportation distance $[16,17]$. To date, var-

\footnotetext{
${ }^{1}$ School of Materials Science and Engineering, Central South University, Changsha 410083, China

2 Department of Materials Science \& Engineering, University of Washington, Seattle, WA 98195, USA

These authors contributed equally to this work.

* Corresponding authors (emails: zhut0002@csu.edu.cn (Zhu T); pananqiang@csu.edu.cn (Pan A))
} 
ious $\mathrm{SnS}_{2}$ hierarchical microstructures with different morphologies, such as microflowers [18], microspheres [19], microplates [10] and microbelts [20], were synthesized to improve the electrochemical properties. Furthermore, carbon materials are introduced into $\mathrm{SnS}_{2}$ microstructures as the conductive agent to increase the electrical conductivity of the electrode materials [21,22]. For example, Kong et al. [23] fabricated free-standing $\mathrm{SnS}_{2} @$ graphene microcables, with a stable specific capacity of $720 \mathrm{~mA} \mathrm{~h} \mathrm{~g}^{-1}$ at a current density of $0.2 \mathrm{~A} \mathrm{~g}^{-1}$. Liu et al. [24] reported a $3 \mathrm{D}$ free-standing $\mathrm{SnS}_{2}$ with polypyrrole-microbelt and carbon-microtube, which showed a capacity of $757 \mathrm{~mA} \mathrm{~h} \mathrm{~g}^{-1}$ at a current density of $1 \mathrm{C}$. Based on the above reported work, a speculation can be made that carbon structures can enhance the physical property by serving as conductive agents, ion channel and volume expansion buffer in the $\mathrm{SnS}_{2} @ \mathrm{C}$ structure. So, it would be feasible to design a sophisticated $\mathrm{SnS}_{2} / \mathrm{C}$ composite, which provides enough space for the volume extraction and contraction of $\mathrm{SnS}_{2}$ and good contact between the active material and carbon.

Herein, we successfully constructed carbon-coated $\mathrm{SnS}_{2}$ hollow microspheres by a sulfurization of carbon coated $\mathrm{SnO}_{2}$ hollow spheres. In this case, the hollow structures and protective carbon shells can effectively buffer the volumetric expansion of inner $\mathrm{SnS}_{2}$ electroactive materials as well as preserve the structural integrity of the whole structures $[25,26]$. As illustrated in Scheme 1, the detailed formation process of the $\mathrm{SnS}_{2} @ \mathrm{C}$ hollow microspheres involves three steps. In the presence of urea and potassium stannate in an ethanol solution, $\mathrm{SnO}_{2}$ hollow microspheres were fabricated by a facile hydrothermal method (step I). The as-synthesized $\mathrm{SnO}_{2}$ hollow microspheres were then uniformly coated with glucose-derived carbon species in a subsequent hydrothermal process to generate $\mathrm{SnO}_{2} @ \mathrm{C}$ core-shell structures (step II). In sulfurization process (step III, the last step), the as-formed $\mathrm{SnO}_{2} @ \mathrm{C}$ core-shell structures were mixed with thiourea as a sulfur source and annealed in a vacuum atmosphere to obtain $\mathrm{SnS}_{2} @ \mathrm{C}$ hollow microspheres. The core-shell $\mathrm{SnS}_{2} @ \mathrm{C}$ exhibit good electrochemical properties as anode materials for lithium ion batteries.

\section{EXPERIMENTAL SECTION}

\section{Synthesis of $\mathrm{SnO}_{2}$ hollow microspheres}

In a typical synthesis, $\mathrm{K}_{2} \mathrm{SnO}_{3} \cdot \mathrm{H}_{2} \mathrm{O}(0.384 \mathrm{~g})$ and urea $(0.96 \mathrm{~g})$ were dissolved into $80 \mathrm{~mL}$ of mixed solution (50 mL distilled water and $30 \mathrm{~mL}$ ethanol) under moderate stirring for $5 \mathrm{~min}$, and a white translucent suspension was obtained. Then the suspension was transferred into a Teflon-lined autoclave and heated at $190^{\circ} \mathrm{C}$ for $15 \mathrm{~h}$. After the solution was cooled down naturally, the white product was collected by centrifugation and washed with ethanol and water for six times before dried at $50^{\circ} \mathrm{C}$ overnight in a vacuum oven.

\section{Synthesis of $\mathrm{SnS}_{2}$ hollow microspheres}

Carbon coating of $\mathrm{SnO}_{2}$ hollow microspheres was conducted by a facile hydrothermal treatment. In a typical procedure, $0.15 \mathrm{~g}$ of the as-synthesized $\mathrm{SnO}_{2}$ powder and $0.6 \mathrm{~g}$ glucose were added to a mixture of distilled water and ethanol before stirring for $10 \mathrm{~min}$. The mixture was hydrothermally treated at $190^{\circ} \mathrm{C}$ for $10 \mathrm{~h}$ and cooled down naturally. The brown product was collected by centrifugation and washed with ethanol for six times before dried at $50^{\circ} \mathrm{C}$ in a vacuum oven for $12 \mathrm{~h}$. Finally, the as-obtained $\mathrm{SnO}_{2} @ \mathrm{C}$ powder was sulfurized in a vacuum atmosphere at $350^{\circ} \mathrm{C}$ for $12 \mathrm{~h}$ by the introduction of thiourea during the heat treatment.

\section{Electrochemical measurements}

The as-prepared $\mathrm{SnS}_{2} @ \mathrm{C}$ microspheres, acetylene black and polyvinylidene fluoride (PVDF) binder (with a weight ratio of $8: 1: 1)$ were stirred with a solution of $N$ methyl-2-pyrrolidone (NMP) to form a homogeneous slurry. The well-mixed slurry was then coated onto a copper foil and dried at $90^{\circ} \mathrm{C}$ overnight in a vacuum oven

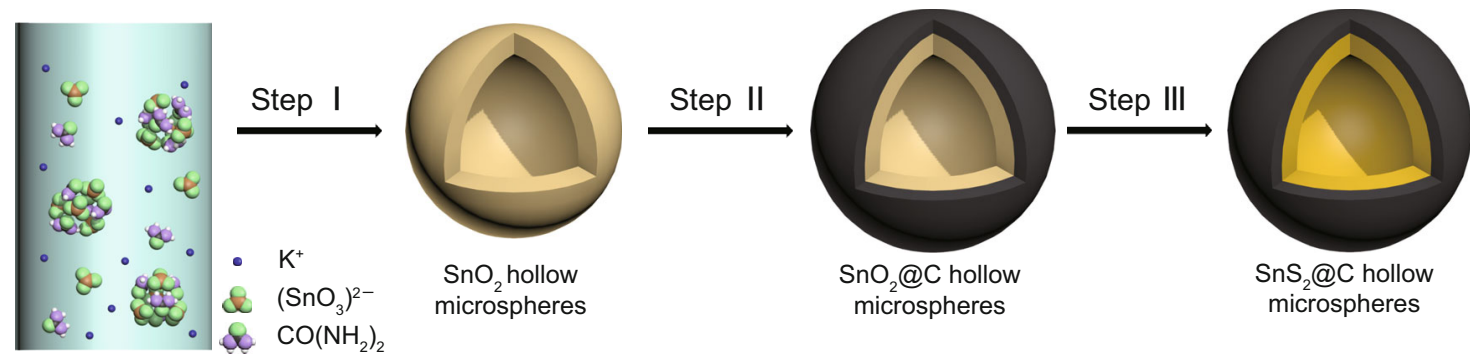

Scheme 1 Schematic illustration of the formation of $\mathrm{SnS}_{2} @ \mathrm{C}$ hollow microspheres. 

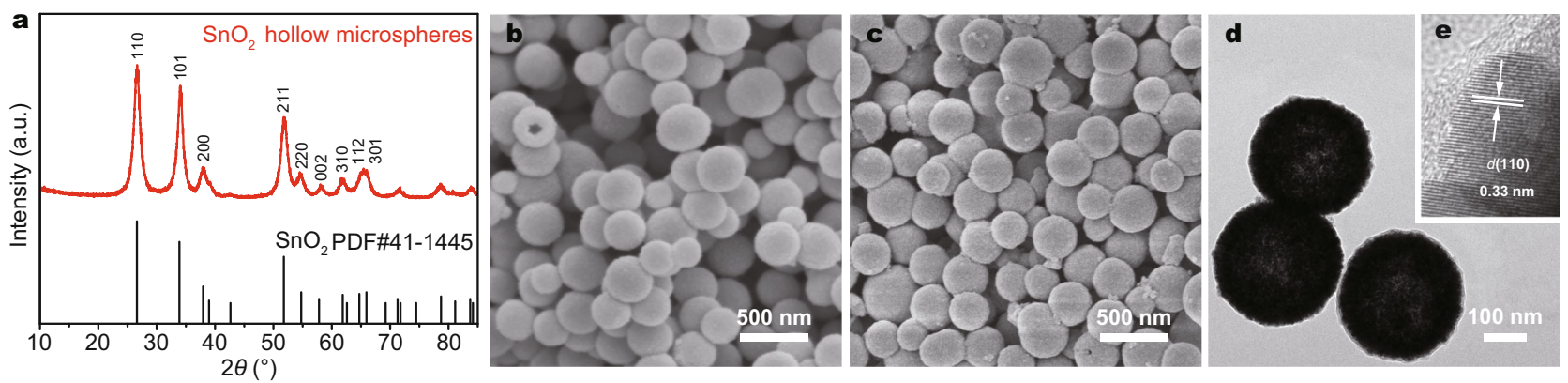

Figure 1 Characterizations of the precursors. (a) XRD pattern of the $\mathrm{SnO}_{2}$; (b) SEM of the $\mathrm{SnO}_{2}$; (c) SEM of the SnO $@$ @; TEM (d) and HR-TEM (e) images of the $\mathrm{SnO}_{2} @ \mathrm{C}$.

to obtain the anodes with a diameter of $12 \mathrm{~mm}$. Coin cells were assembled in an ultra-high purity argon-filled glove box (Mbraun, Germany) using microporous polypropylene membrane as a separator, $\mathrm{Li}$ metal foil as the counter electrode and $1 \mathrm{~mol} \mathrm{~L}^{-1} \mathrm{LiPF}_{6}$ (dissolved in ethylene carbonate/dimethylcarbonate/diethyl carbonate, $\mathrm{EC} / \mathrm{DMC} / \mathrm{DEC}=1: 1: 1$ in volume) as the electrolyte. The charge-discharge performances between 0.01 to $3 \mathrm{~V}$ ( $v s$. $\left.\mathrm{Li} / \mathrm{Li}^{+}\right)$of the cells were recorded in Land Battery Tester (Land CT 2001A, Wuhan, China). Cyclic voltammetry (CV) was carried out using an electrochemical workstation (CHI660C, China) in a voltage range of $0.01-3 \mathrm{~V}$ (vs. $\mathrm{Li} / \mathrm{Li}^{+}$) at a scan rate of $0.05 \mathrm{mV} \mathrm{s}^{-1}$.

\section{RESULTS AND DISCUSSION}

The crystallographic structures of the precursors were first examined by the X-ray diffraction (XRD) and the results are shown in Fig. 1a. The XRD pattern of the $\mathrm{SnO}_{2}$ hollow microspheres can be assigned to tetragonal phase of $\mathrm{SnO}_{2}$ (JCPDS No.41-1445, p42/mnm (136), $a=b$ $=4.738 \AA, c=3.187 \AA$ ). Fig. $1 \mathrm{~b}$ shows the scanning electron microscopy (SEM) images of the $\mathrm{SnO}_{2}$ hollow microspheres, which have good uniformity with an average diameter of $300 \mathrm{~nm}$. The formation of the $\mathrm{SnO}_{2}$ hollow microspheres can be explained by an inside-out Ostwald ripening mechanism. The white translucent suspension is produced by the hydrolysis of stannate. The inside-out ripening causes the dissolution of inner part of precipitation and finally results in the hollow interiors during hydrothermal process [6]. From the SEM image of $\mathrm{SnO}_{2} @ \mathrm{C}$ shown in Fig. 1c, a rough surface of the spheres can be observed. Meanwhile, no obvious morphological and structural changes can be found after carbon-coating, revealing the structural robustness of the spheres. The interior structure of the $\mathrm{SnO}_{2} @ \mathrm{C}$ microspheres were investigated by transmission electron microscopy (TEM) and high-resolution TEM (HRTEM). As shown in Fig. 1d, e, the periphery of microspheres shows a distinct contrast to the central part, indicating hollow interior of the spheres. The lattice fringes shown in a HRTEM image (Fig. 2d) indicate a good crystallinity with an interplanar distance of $0.33 \mathrm{~nm}$, which is in good accordance with the $\mathrm{d}$-spacing values of tetragonal $\mathrm{SnO}_{2}$ (110). The amorphous carbon coating layer is clearly observed on the surface of the $\mathrm{SnO}_{2}$ hollow microspheres $[6,8]$.

After sulfurization with thiourea in vacuum, the $\mathrm{SnO}_{2} @ \mathrm{C}$ hollow microspheres were transformed into $\mathrm{SnS}_{2} @ \mathrm{C}$ hollow microspheres. The crystal phase of the $\mathrm{SnS}_{2} @ \mathrm{C}$ can be confirmed by the presence of the XRD peaks (Fig. 2a), consistent with the hexagonal $\mathrm{SnS}_{2}$ phase (JCPDS No. 83-1705, $p$-3m1(164), $a=b=3.638 \AA, \quad c$ $=5.880 \AA$ ). Raman testing of the $\mathrm{SnS}_{2} @ \mathrm{C}$ provided the evidence for the existence of carbon in the final products (Fig. 2b). Raman peaks that appear at the wave number around 1350 and $1580 \mathrm{~cm}^{-1}$ can be assigned to the Dband and G-band of carbon species, respectively [27]. Specifically, G-band represents the graphitic feature, while D-band signifies the disorder degree of carbon caused by the existence of tiny crystalline grains [28]. The thermal gravimetric analysis (TGA) and differential thermal analysis (DTA) were operated on the $\mathrm{SnS}_{2} @ \mathrm{C}$ sample, and the curves are shown in Fig. 2c. The peak of DTA curve at about $450^{\circ} \mathrm{C}$ corresponds to the oxidation of $\mathrm{SnS}_{2}$, and the carbon in sample began to burn at $500^{\circ} \mathrm{C}$. According to the weight change of TGA curve, the content of carbon in the $\mathrm{SnS}_{2} @ \mathrm{C}$ is about 14\%. The SEM image of $\mathrm{SnS}_{2} @ \mathrm{C}$ (Fig. 2d) shows no distinct structural changes after sulfurization compared to the $\mathrm{SnO}_{2}$ and $\mathrm{SnO}_{2} @ \mathrm{C}$ microspheres, indicating the good structural reservation of the carbon coated $\mathrm{SnS}_{2}$ spheres. Fig. 2e shows the TEM image of $\mathrm{SnO}_{2} @ \mathrm{C}$ microspheres, indicating a hollow interior of the microsphere. An HRTEM image (Fig. 2f) further elucidates that the $\mathrm{SnS}_{2}$ microspheres were coated by amorphous carbon with an 

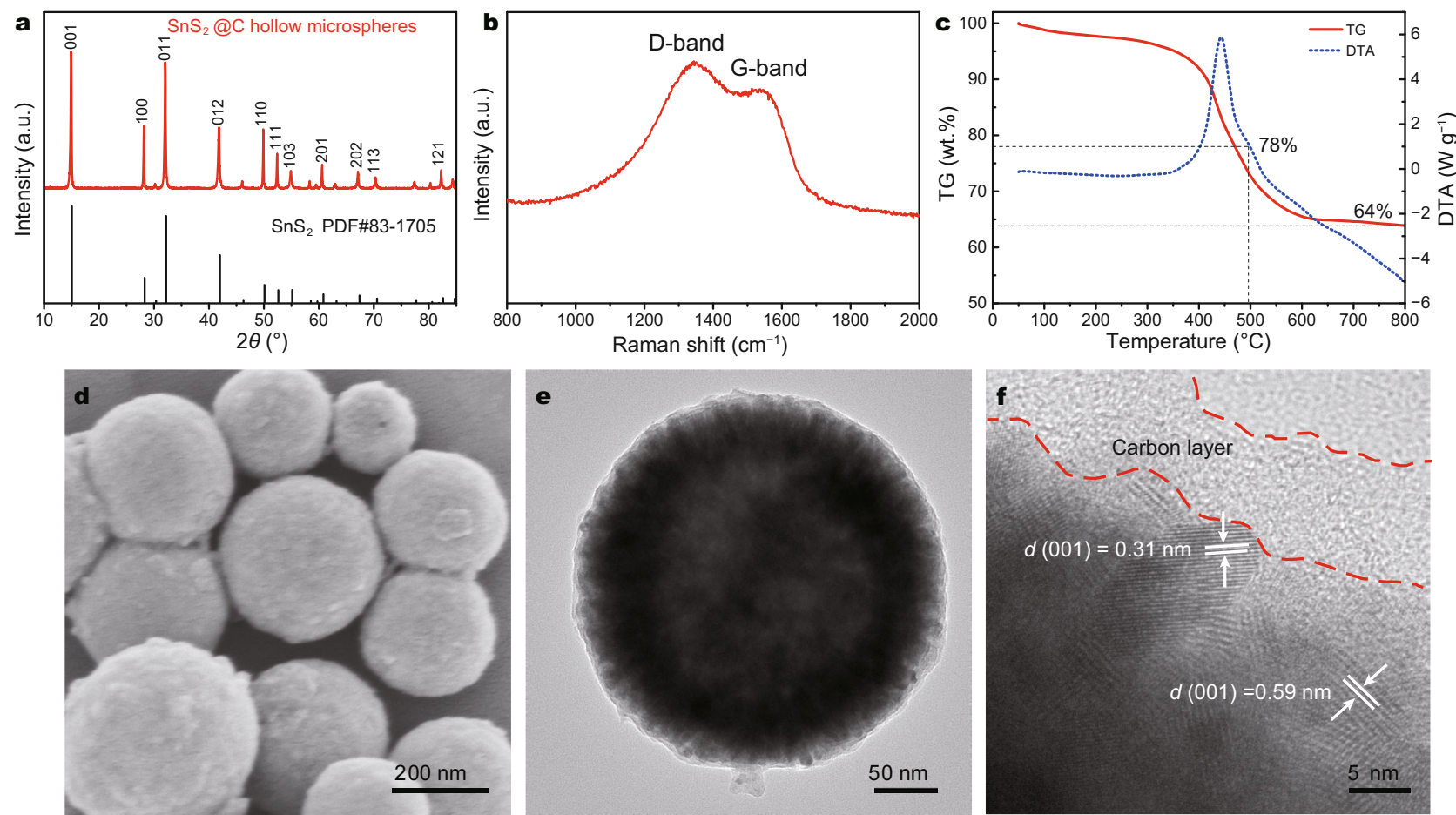

Figure 2 Characterizations of the SnS $2 @$ C microspheres. (a) XRD patterns; (b) Raman curve; (c) TGA\&DTA curves; SEM (d), TEM (e) and HRTEM (f) images.

average thickness of $\sim 10 \mathrm{~nm}$ (marked by red dashed line). Two typical lattice fringes were measured and their interplanar spacing are 0.31 and $0.59 \mathrm{~nm}$, respectively, which are in good accordance to the planar distances of (100) and (001) for $\mathrm{SnS}_{2}$, indicating the spheres are composed of polycrystalline grains with a high crystallinity. The TEM results again certify that the carbon layer was successfully coated onto the microspheres while the hollow structures from the $\mathrm{SnO}_{2}$ have been entirely preserved.

\section{Electrochemical performance}

The electrochemical performances of the as-prepared $\mathrm{SnS}_{2} @ \mathrm{C}$ hollow microspheres are shown in Fig. 3. Fig. 3a displays the first three CV curves of the electrode within a voltage window of $0.01-3.0 \mathrm{~V}\left(v s . \mathrm{Li} / \mathrm{Li}^{+}\right)$at a scan rate of $0.1 \mathrm{mV} \mathrm{s}^{-1}$. Typically, four reduction peaks can be found in cathodic scans from the CV curves. The reduction peak at $1.83 \mathrm{~V}\left(v s . \mathrm{Li} / \mathrm{Li}^{+}\right)$is known to arise from the lithium intercalation into $\mathrm{SnS}_{2}$ without a phase decomposition (Equation (1)) [29,30]. The reduction peaks at 1.62 and $1.19 \mathrm{~V}\left(v s . \mathrm{Li} / \mathrm{Li}^{+}\right)$in the first cathodic sweep could be attributed to the decomposition of $\mathrm{SnS}_{2}$ into metallic tin and the formation of $\mathrm{Li}_{2} \mathrm{~S}$ (Equation (2)), which may occur in three steps [30], as well as the formation of a solid electrolyte interface (SEI) [11,31]. The peak at $0.22 \mathrm{~V}\left(v s . \mathrm{Li} / \mathrm{Li}^{+}\right)$in the first anodic scan corresponds to the reversible formation of $\mathrm{Li}_{x} \mathrm{Sn}$ alloy (Equation (3)) and the oxidation peak at $0.50 \mathrm{~V}\left(v s . \mathrm{Li} / \mathrm{Li}^{+}\right)$in the first anodic scan possibly originates from the delithiation reaction of $\mathrm{Li}_{x} \mathrm{Sn}$ alloy (Equation (3)). The above kinetics can be described by the electro-chemical conversion reactions $[30,32]$

$$
\begin{gathered}
\mathrm{SnS}_{2}+x \mathrm{Li}^{+}+x \mathrm{e}^{-} \rightarrow \mathrm{Li}_{x} \mathrm{SnS}_{2}, \\
\mathrm{Li}_{x} \mathrm{SnS}_{2}+(4-x) \mathrm{Li}^{+}+(4-x) \mathrm{e}^{-} \rightarrow \mathrm{Sn}+2 \mathrm{Li}_{2} \mathrm{~S} \\
\mathrm{Sn}+4.4 \mathrm{Li}^{+}+4.4 \mathrm{e}^{-} \rightarrow \mathrm{Li}_{4.4} \mathrm{Sn} .
\end{gathered}
$$

The galvanostatic charge/discharge measurements of the $\mathrm{SnS}_{2} @ \mathrm{C}$ hollow microsphere anodes were performed within a voltage range of $0.01-3.0 \mathrm{~V}$ at a current density of $100 \mathrm{~mA} \mathrm{~g}^{-1}$ (Fig. 3b). The composite electrode delivers specific capacities of 1320 and $850 \mathrm{~mA} \mathrm{~h} \mathrm{~g}^{-1}$ for the first discharge and charge processes, respectively. The large initial capacity loss has led to a low coulombic efficiency of the first cycle (64\%), which is attributed to the irreversible loss of $\mathrm{Li}$ ions resulting from the formation of an SEI layer on the electrode as well as partially irreversible decomposition of $\mathrm{SnS}_{2}$ [33,34]. Although the first reversible discharge capacity decayed to $850 \mathrm{~mA} \mathrm{~g}^{-1}$, the $\mathrm{SnS}_{2} @ \mathrm{C}$ hollow microsphere anode showed a con- 

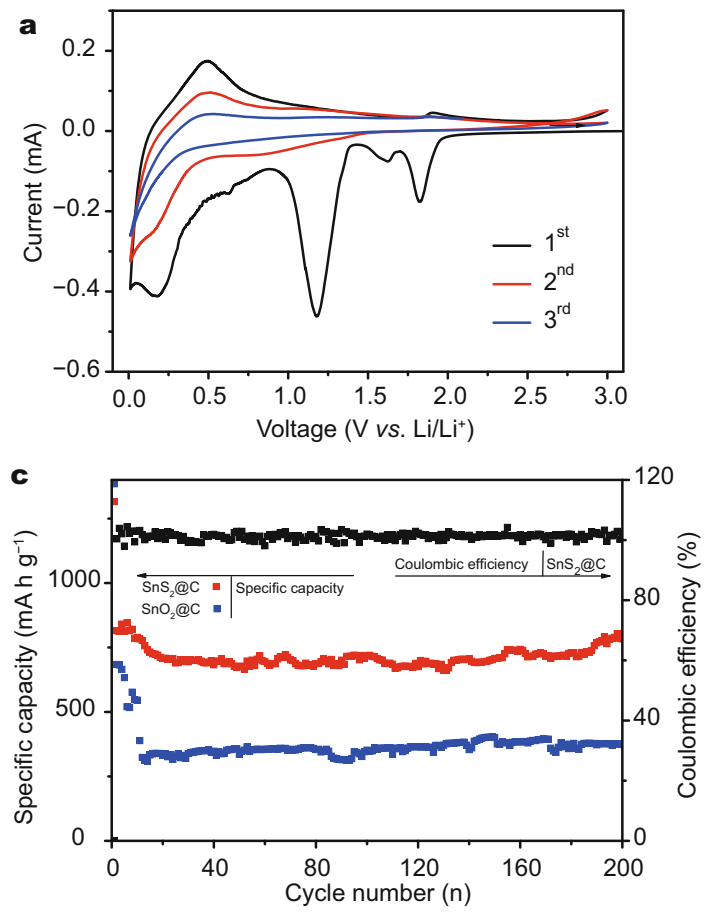
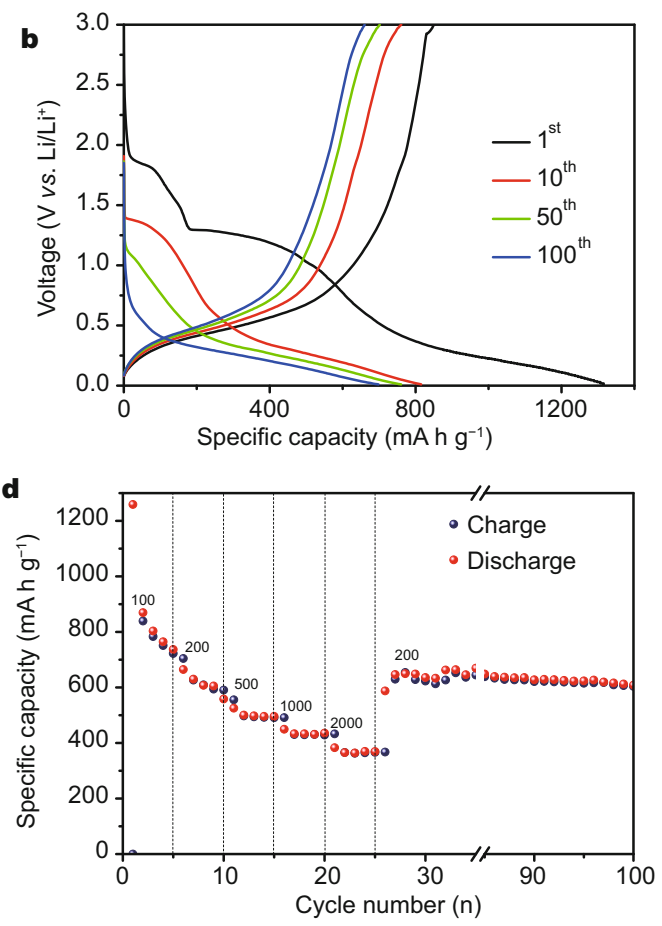

Figure 3 Electrochemical performances of the $\mathrm{SnS}_{2} @ \mathrm{C}$ and $\mathrm{SnO}_{2} @ \mathrm{C}$ hollow microsphere electrodes. (a) First three CV curves; (b) galvanostatic discharge/charge curves; cycling performances at a current density of $100 \mathrm{~mA} \mathrm{~g}^{-1}$ (c) and rate performances (d) of SnS $\mathrm{C}_{2}$.

siderably stable cycling performance after the first several cycles (Fig. 3c). The specific capacity remained at a very high value of $812 \mathrm{~mA} \mathrm{~h} \mathrm{~g}^{-1}$ after 200 cycles with a high capacity retention of $95.5 \%$ (Fig. 3c). Because the reversible capacity of $\mathrm{SnS}_{2}$ is $645 \mathrm{~mA} \mathrm{~h} \mathrm{~g}^{-1}$ [10], and its irreversible capacity would gradually fade in the initial cycles, the extra capacity could be contributed by the carbon at about $170 \mathrm{~mA} \mathrm{~h} \mathrm{~g}^{-1}$. The fluctuation of capacity during the cycle test could be possibly caused by the testing environment. The tiny fluctuation of temperature, humidity, and power supply may lead to the capacity fluctuations of the battery cells. Meanwhile, the cycle performance of $\mathrm{SnO}_{2} @ \mathrm{C}$ has been tested as a comparison (Fig. 3c). Although the first-discharge capacity is a little higher, it decreased to less than $400 \mathrm{~mA} \mathrm{~h} \mathrm{~g}^{-1}$ within the next 20 cycles, showing its worse performance than that of $\mathrm{SnS}_{2} @ \mathrm{C}$. Compared to some of the previous work, the $\mathrm{SnS}_{2} @ \mathrm{C}$ reported in this work exhibited good electrochemical performance in specific capacities and cycle stability. For example, in a study by Luo et al. [35], the $\mathrm{SnS}_{2}$-anode showed an initial discharge capacity as high as $1900 \mathrm{~mA} \mathrm{~h} \mathrm{~g}^{-1}$, but the first reversible discharge capacity fell to $687 \mathrm{~mA} \mathrm{~h} \mathrm{~g}^{-1}$. In another study by Yin et al. [36], the specific capacity of $913 \mathrm{~mA} \mathrm{~h} \mathrm{~g}^{-1}$ dropped to $547 \mathrm{~mA} \mathrm{~h} \mathrm{~g}^{-1}$ quickly after 50 cycles, although the first reversible discharge capacity was high.

Discharge/charge specific capacities of the $\mathrm{SnS}_{2} @ \mathrm{C}$ hollow microspheres at various current densities shown in Fig. 3d verifies their superior rate capability as anodes for LIBs. The specific discharge capacities are 780, 598, 500,412 and $378 \mathrm{~mA} \mathrm{~h} \mathrm{~g}^{-1}$ at the current densities of 100 , 200, 500, 1000 and $2000 \mathrm{~mA} \mathrm{~g}^{-1}$, respectively. When the current rate was reset to $200 \mathrm{~mA} \mathrm{~g}^{-1}$, a stable specific discharge capacity of approximately $606 \mathrm{~mA} \mathrm{~h} \mathrm{~g}^{-1}$ can be obtained. The capacity in the last 75 cycles is more stable than that at the same current rate of $200 \mathrm{~mA} \mathrm{~g}^{-1}$ in the 5$10^{\text {th }}$ cycles. It may be due to the various irreversible processes at earlier working stage of battery. Capacity would gradually decrease under the synergistic effects of side reactions like the formation of SEI, irreversible phase change of $\mathrm{SnS}_{2}$, and decomposition of electrolyte. Thus the capacity would become more stable when the side reactions come to a certain to reach an equilibrium. The good electrochemical performances at high current densities of these $\mathrm{SnS}_{2} @ \mathrm{C}$ hollow microsphere show their superiority over those previously reported $\mathrm{SnS}_{2}$, such as graphene sheets-supported $\mathrm{SnS}_{2}$ nanoplates in a study by Jiang et al. [37]. Therein the discharge capacity of the LIBs decayed from 642 to $240 \mathrm{~mA} \mathrm{~g}^{-1}$ when the current densities changed from 50 to $1000 \mathrm{~mA} \mathrm{~g}^{-1}$. Three-di- 
mensional $\mathrm{SnS}_{2}$ hierarchitectures prepared by $\mathrm{Wu}$ et al. [38] demonstrated a discharge capacity of $706 \mathrm{~mA} \mathrm{~h} \mathrm{~g}^{-1}$ at $100 \mathrm{~mA} \mathrm{~g}^{-1}$ but decreased to $210 \mathrm{~mA} \mathrm{~h} \mathrm{~g}^{-1}$ at $1000 \mathrm{~mA} \mathrm{~g}^{-1}$. As a whole, the above-discussed experimental results demonstrate good electrochemical properties of the $\mathrm{SnS}_{2} @ \mathrm{C}$ hollow microspheres. The superior LIBs performances of this electrode material can be explained as follows: (i) the hollow structures of the $\mathrm{SnS}_{2} @ \mathrm{C}$ could provide extra interior space to accommodate the volume expansion/contraction during the $\mathrm{Li}^{+}$insertion/ extraction process [39]. (ii) The carbon shells prevented the restacking of $\mathrm{SnS}_{2}$ microspheres or the crumbling of electrode material during continuous cycling [40]. (iii) The coated amorphous carbon in the composite can serve as the conductive species, which decrease the inner resistance of the LIBs, thus leading to a higher specific capacity and better rate capability [41].

\section{CONCLUSIONS}

In summary, hollow $\mathrm{SnS}_{2}$ microspheres for LIBs anodes have been successfully synthesized by a facile method. The microspheres were completely protected by a layer of thin, conformal and self-supporting amorphous carbon shell. The rationally designed interior hollow allows a space for the expansion of $\mathrm{SnS}_{2}$ without deforming the carbon shell. Owing to these unique structural features, the as-obtained $\mathrm{SnS}_{2} @ \mathrm{C}$ microspheres exhibit a very high reversible capacity of $850 \mathrm{~mA} \mathrm{~h} \mathrm{~g}^{-1}$ and reserve a value of $812 \mathrm{~mA} \mathrm{~h} \mathrm{~g}^{-1}$ after 200 cycles. Furthermore, they also show a superior rate capability. The results suggest their great potential as anode materials for the next-generation LIBs.

Received 29 June 2017; accepted 14 August 2017; published online 27 September 2017

1 Tarascon JM, Poizot P, Laruelle S, et al. Nano-sized transitionmetal oxides as negative-electrode materials for lithium-ion batteries. Nature, 2000, 407: 496-499

2 Nam KT, Kim DW, Yoo PJ, et al. Virus-enabled synthesis and assembly of nanowires for lithium ion battery electrodes. Science, 2006, 312: 885-888

$3 \mathrm{Lu} \mathrm{Z}, \mathrm{Wu} \mathrm{X}$, Jiang M, et al. Transition metal oxides/hydroxides nanoarrays for aqueous electrochemical energy storage systems. Sci China Mater, 2014, 57: 59-69

4 Etacheri V, Marom R, Elazari R, et al. Challenges in the development of advanced Li-ion batteries: a review. Energ Environ Sci, 2011, 4: 3243

5 Pan A, Wang Y, Xu W, et al. High-performance anode based on porous $\mathrm{Co}_{3} \mathrm{O}_{4}$ nanodiscs. J Power Sources, 2014, 255: 125-129

6 Lou XW, Wang Y, Yuan C, et al. Template-free synthesis of $\mathrm{SnO}_{2}$ hollow nanostructures with high lithium storage capacity. Adv Mater, 2006, 18: 2325-2329
$7 \mathrm{Xu} \mathrm{W}$, Xie Z, Cui X, et al. Hierarchical graphene-encapsulated hollow $\mathrm{SnO}_{2} @ \mathrm{SnS}_{2}$ nanostructures with enhanced lithium storage capability. ACS Appl Mater Interfaces, 2015, 7: 22533-22541

$8 \mathrm{Xu} \mathrm{W}$, Zhao K, Niu C, et al. Heterogeneous branched core-shell $\mathrm{SnO}_{2}$-PANI nanorod arrays with mechanical integrity and three dimentional electron transport for lithium batteries. Nano Energy, 2014, 8: 196-204

9 Sun Z, Liao T, Kou L. Strategies for designing metal oxide nanostructures. Sci China Mater, 2016, 60: 1-24

10 Seo J, Jang J, Park S, et al. Two-dimensional $\mathrm{SnS}_{2}$ nanoplates with extraordinary high discharge capacity for lithium ion batteries. Adv Mater, 2008, 20: 4269-4273

11 Mei L, Xu C, Yang T, et al. Superior electrochemical performance of ultrasmall $\mathrm{SnS}_{2}$ nanocrystals decorated on flexible RGO in lithium-ion batteries. J Mater Chem A, 2013, 1: 8658-8664

12 Zhai C, Du N, Yang HZD. Large-scale synthesis of ultrathin hexagonal tin disulfidenanosheets with highly reversible lithium storage. Chem Commun, 2011, 47: 1270-1272

13 Mukaibo H, Yoshizawa A, Momma T, et al. Particle size and performance of $\mathrm{SnS}_{2}$ anodes for rechargeable lithium batteries. J Power Sources, 2003, 119-121: 60-63

14 Mahmood N, Hou Y. Electrode nanostructures in lithium-based batteries. Adv Sci, 2014, 1: 1400012

15 Lee KT, Jung YS, Oh SM. Synthesis of tin-encapsulated spherical hollow carbon for anode material in lithium secondary batteries. J Am Chem Soc, 2003, 125: 5652-5653

16 Xia $\mathrm{H}$, Xiong W, Lim CK, et al. Hierarchical $\mathrm{TiO}_{2}-\mathrm{B}$ nanowire@a$\mathrm{Fe}_{2} \mathrm{O}_{3}$ nanothorn core-branch arrays as superior electrodes for lithium-ion microbatteries. Nano Res, 2014, 7: 1797-1808

17 Xia H, Xia Q, Lin B, et al. Self-standing porous $\mathrm{LiMn}_{2} \mathrm{O}_{4}$ nanowall arrays as promising cathodes for advanced $3 \mathrm{D}$ microbatteries and flexible lithium-ion batteries. Nano Energy, 2016, 22: 475-482

18 Ma J, Lei D, Duan X, et al. Designable fabrication of flower-like $\mathrm{SnS}_{2}$ aggregates with excellent performance in lithium-ion batteries. RSC Adv, 2012, 2: 3615-3617

19 Xia J, Li G, Mao Y, et al. Hydrothermal growth of $\mathrm{SnS}_{2}$ hollow spheres and their electrochemical properties. CrystEngComm, 2012, 14: 4279-4283

20 Wang J, Liu J, Xu H, et al. Gram-scale and template-free synthesis of ultralong tin disulfide nanobelts and their lithium ion storage performances. J Mater Chem A, 2013, 1: 1117-1122

21 Liu Y, Kang H, Jiao L, et al. Exfoliated-SnS 2 restacked on graphene as a high-capacity, high-rate, and long-cycle life anode for sodium ion batteries. Nanoscale, 2015, 7: 1325-1332

22 An C, Liu X, Gao Z, et al. Filling and unfilling carbon capsules with transition metal oxide nanoparticles for Li-ion hybrid supercapacitors: towards hundred grade energy density. Sci China Mater, 2017, 60: 217-227

23 Kong D, He H, Song Q, et al. A novel SnS ${ }_{2} @$ graphene nanocable network for high-performance lithium storage. RSC Adv, 2014, 4: 23372-23376

24 Liu J, Wen Y, van Aken PA, et al. In situ reduction and coating of $\mathrm{SnS}_{2}$ nanobelts for free-standing SnS@polypyrrole-nanobelt/carbon-nanotube paper electrodes with superior Li-ion storage. J Mater Chem A, 2015, 3: 5259-5265

25 Wei Seh Z, Li W, Cha JJ, et al. Sulphur- $\mathrm{TiO}_{2}$ yolk-shell nanoarchitecture with internal void space for long-cycle lithiumsulphur batteries. Nat Commun, 2013, 4: 1331

26 Nie Z, Wang Y, Zhang Y, et al. Multi-shelled $\alpha-\mathrm{Fe}_{2} \mathrm{O}_{3}$ microspheres for high-rate supercapacitors. Sci China Mater, 2016, 59: 247-253 
27 Qin L, Liang S, Pan A, et al. $\mathrm{Zn}_{2} \mathrm{SnO}_{4} /$ carbon nanotubes composite with enhanced electrochemical performance as anode materials for lithium-ion batteries. Mater Lett, 2016, 164: 44-47

28 Qin L, Liang S, Tan $\mathrm{X}$, et al. $\mathrm{Zn}_{2} \mathrm{SnO}_{4}$ /graphene composites as anode materials for high performance lithium-ion batteries. J Alloys Compd, 2017, 692: 124-130

29 Zhuo L, Wu Y, Wang L, et al. One-step hydrothermal synthesis of $\mathrm{SnS}_{2}$ /graphene composites as anode material for highly efficient rechargeable lithium ion batteries. RSC Adv, 2012, 2: 5084-5087

30 Kim TJ, Kim C, Son D, et al. Novel $\mathrm{SnS}_{2}$-nanosheet anodes for lithium-ion batteries. J Power Sources, 2007, 167: 529-535

31 Zhang Q, Li R, Zhang M, et al. $\mathrm{SnS}_{2} /$ reduced graphene oxide nanocomposites with superior lithium storage performance. Electrochim Acta, 2014, 115: 425-433

32 Wang G, Peng J, Zhang L, et al. Two-dimensional SnS $2 @ P A N I$ nanoplates with high capacity and excellent stability for lithiumion batteries. J Mater Chem A, 2015, 3: 3659-3666

33 Liu J, Wen Y, van Aken PA, et al. Facile synthesis of highly porous $\mathrm{Ni}-\mathrm{Sn}$ intermetallic microcages with excellent electrochemical performance for lithium and sodium storage. Nano Lett, 2014, 14: 6387-6392

34 Liu J, Wen Y, Wang Y, et al. Carbon-encapsulated pyrite as stable and earth-abundant high energy cathode material for rechargeable lithium batteries. Adv Mater, 2014, 26: 6025-6030

35 Luo B, Fang Y, Wang B, et al. Two dimensional grapheme-SnS hybrids with superior rate capability for lithium ion storage. Energy Environ Sci, 2012, 5: 5226-5230

36 Yin L, Chai S, Ma J, et al. Effects of binders on electrochemical properties of the $\mathrm{SnS}_{2}$ nanostructured anode of the lithium-ion batteries. J Alloys Compd, 2017, 698: 828-834
37 Jiang X, Yang X, Zhu Y, et al. In situ assembly of graphene sheetssupported $\mathrm{SnS}_{2}$ nanoplates into 3D macroporous aerogels for highperformance lithium ion batteries. J Power Sources, 2013, 237: 178-186

38 Wu Q, Jiao L, Du J, et al. One-pot synthesis of three-dimensional $\mathrm{SnS}_{2}$ hierarchitectures as anode material for lithium-ion batteries. J Power Sources, 2013, 239: 89-93

39 Zeng L, Pan A, Liang S, et al. Novel synthesis of $\mathrm{V}_{2} \mathrm{O}_{5}$ hollow microspheres for lithium ion batteries. Sci China Mater, 2016, 59: 567-573

40 Wang YG, Wu W, Cheng $\mathrm{L}$, et al. A polyaniline-intercalated layered manganese oxide nanocomposite prepared by an inorganic/organic interface reaction and its high electrochemical performance for Li storage. Adv Mater, 2008, 20: 2166-2170

41 Zheng L, Xu Y, Jin D, et al. Polyaniline-intercalated molybdenum oxide nanocomposites: simultaneous synthesis and their enhanced application for supercapacitor. Chem Asian J, 2011, 6: 1505-1514

Acknowledgements This work was supported by the National Natural Science Foundation of China (51302323), the Program for New Century Excellent Talents in University (NCET-13-0594), and the Innovationdriven Project of Central South University (2017CX001).

Author contributions Yang $\mathrm{H}$ and $\mathrm{Su} \mathrm{Y}$ performed the experiments and wrote the article; Ding L participated in the experiments; Lin J performed the data analysis; Pan A and Zhu T proposed the experimental design. All authors contributed to the general discussion.

Conflict of interest The authors declare that they have no conflict of interest. 


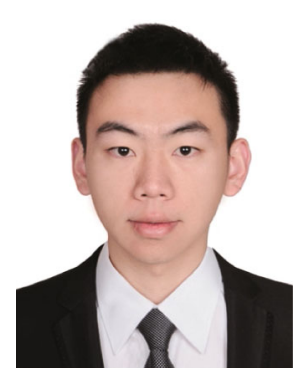

Hulin Yang is a postgraduate student in Prof. Pan's Group and will receive his Master degree from the School of Materials Science and Engineering at Central South University soon in 2018. His current research interest is tin-based materials for anode of lithium ion battery.

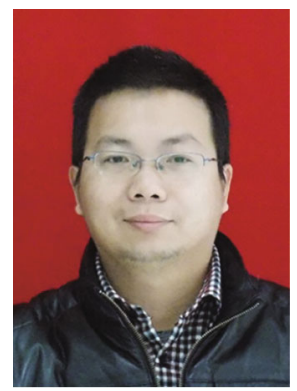

Anqiang Pan is currently a full professor at the School of Materials Science and Engineering, Central South University. His research interests focus on the synthesis of electrochemical energy storage materials and their applications, such as lithium ion batteries, supercapacitors and catalysts.

\section{定向合成用于锂离子电池的高稳定性 $\mathrm{SnS}_{2} @ \mathrm{C}$ 空心微米球}

杨岵林 ${ }^{1}$, 苏艳辉 ${ }^{1}$, 丁琳 $^{1}$, 林建德 $^{1}$, 朱挺 $^{1^{*}}$, 梁叔全 $^{1}$, 潘安强 $^{1^{*}}$, 曹国忠 ${ }^{2}$

摘要 锡基材料作为锂离子电池高容量负极材料得到了广泛研究. 然而循环充放电过程中的大体积变化通常会造成电极材料粉化. 本文 报道了水热法合成 $\mathrm{SnO}_{2} @ \mathrm{C}$ 空心微米球, 再对其进行固相硫化制备 $\mathrm{SnS}_{2} @ \mathrm{C}$ 空心微米球的方法. 制得的 $\mathrm{SnS}_{2} @ \mathrm{C}$ 空心微米球具有独特的碳外 壳及空心结构, 用作锂离子电池电极材料时, 在 $100 \mathrm{~mA} \mathrm{~g}^{-1}$ 电流密度下表现出 $814 \mathrm{~mA} \mathrm{~h} \mathrm{~g}^{-1}$ 的高可逆容量, 优秀的循环性能(循环 200 圈后仍 保留 $783 \mathrm{~mA} \mathrm{~h} \mathrm{~g}^{-1}$, 平均每圈损失 $0.02 \%$ ), 以及出色的倍率容量 $(2 \mathrm{C}$ 时为 $433 \mathrm{~mA} \mathrm{~h} \mathrm{~g}$ ). 其内部空心部分可为充放电循环过程中的体积膨胀 提供额外空间, 同时碳外壳能够保护微米球的完整性. 该 $\mathrm{SnS}_{2} @ \mathrm{C}$ 出色的电化学性能展示出用于下一代锂离子电池负极材料的应用前景. 